\title{
The Need Analysis of Cognitive Competencies Assessment Instruments for 11th Grade English Classes of Senior High School during Covid-19 Pandemic
}

\author{
Wirolawe Kristanto Aryo ${ }^{1}$, Wahyuningsih Nurhayati ${ }^{2}$ and Agustin Maulani ${ }^{3}$ \\ \{kristantoaryowirolawe@gmail.com ${ }^{1}$, nutimaha08@gmail.com² ${ }^{2}$ laniagustin9@gmail.com ${ }^{3}$ \} \\ Jakarta State University, Bekasi ${ }^{1}$, Jakarta State University, Jakarta ${ }^{2}$, Jakarta State University, \\ Bandung $^{3}$
}

\begin{abstract}
Students nowadays are required to master the Higher Order Thinking Skills (HOTS) which are related to cognitive competencies. Therefore, this research is aimed to investigate and analyze the cognitive competences assessment instruments. The sampling data was obtained from the 11th Grade English Classes of Senior High School in Bekasi via online classes during Covid-19 pandemic and was analyzed by using a descriptive qualitative method. Based on the data gained, it revealed the findings as follows: 1) The HOTS (ranging from C4-C6) assessment is not yet applied in the 11th grade senior high school, as the assessment instruments are still on the LOTS (ranging from C1 - C3). 2). The assessment instruments applied were still based on paper and pen, and far from practical matters. Considering the findings above, some experts believe that assessing HOTS is better to be applied with practical based assessment instruments rather than paper and pencil based. By that, it can be concluded the need of current HOTS assessment instruments should include the practical basis. Furthermore, the present research hopefully can be beneficial for related roles in educational levels specifically for Senior High School programs. In addition, this research hopefully can guide assessors assessing cognitive competences assessment instruments in order the quality of assessment instruments can be more advanced in the future. Finally, the assessment instruments are essential aspects in the teaching and learning process to know how further the students can acquire the knowledge, skills, or competences in classrooms.
\end{abstract}

Keywords: need analysis, cognitive competences; assessment; assessment instruments

\section{Introduction}

In the educational field, assessment becomes a crucial part in the teaching and learning procedures [1]. To track the students' achievement in learning language and to recognize students regarding their strengths and weaknesses, assessment is required the most. In addition, another research found out that cognitive-based systems can help teachers to assess students' development regarding what they have gained, especially in the cognitive domain [2]. In that case, assessment is a foremost foundation in gaining and gathering the data about the process of what the students have learned. Otherwise, both teacher and students would never know and comprehend the result or output of students after learning particular materials. 
Recently, in the 21 st century era, assessment of students' cognitive competences is being emphasized as one of the requirements for mankind to be mastered. The intention of explicit concern on twenty-first century skills is to encourage students to gain and to be able to apply these skills in real world situations [3]. In other words, students are trained and provided with cognitive competences in order to face modern society especially in terms of working requirements. As such, the cognitive competence is of the benefit for students to continue and to survive in the 21 st century era.

At this rate, assessment in the 21st must apply cognitive competences in every assessment as one of the requirements in assessing students' ability. For any particular subjects, students are supposed to recognize some facts and concepts and also to be able to think and argue with these facts and concepts in some way. Every time students cope with new problems, provide new ideas, or think originally based on their knowledge, they are definitely transferring and proceeding with what they have learned, and their comprehension grows. Therefore, the important thing which has to be considered in measuring cognitive performance requires a rubrics or main core.

Further, it is stated in Bloom's taxonomy that cognitive performance is categorized into six phases, constructed from the simplest level into a complex level. The phase began from knowledge which is the easiest, comprehension, and application, analysis, synthesis, evaluation is identified as the hardest. Then Anderson and Krathwohl made a revision to Bloom's taxonomy which has changed into remember as the lowest, understand, apply, analyze, evaluate, and lastly create as the highest [4].

Other than taxonomy as the measurement basis in a current condition of assessment to assess students' achievement, information regarding the existing cognitive competences assessment instruments is required such as by comparing internal and external issues to find the possibilities in developing new products [5]. Some previous studies from internal issues in assessment context found that practical assessment also needs cognitive competencies instruments rather than only relying on written assessment even though there is a need for $\mathrm{C} 1$ stage (remembering) such as multiple choice [6]. Another research that focused on how multiple choice infused the cognitive based instrument by increasing the difficulty in the distracter of multiple choice [7].

While the others found that most of the assessment instruments in the level of undergraduate program in the South Sulawesi are still implementing the written / traditional assessment which did not infuse the higher order thinking scale [8]. Meanwhile, another research conducted in the senior high school has a lack of cognitive competences and critical thinking infused in the assessment instruments [9]. The same with the scale of junior high school, the researchers also found that the HOTS implementation has not been developed assessing students [10].

While the external issues in assessment context claimed that $\mathrm{C} 1$ stage (remembering) can make an output for HOTS Assessment ranging from C4-C6 where it focuses on applying knowledge in a real situation or even produce something by combining what students have learned [11], [12]. In addition, measuring HOTS cognitive domain and assessment activity for real life situations will be more effective using practice rather than traditional one [13]- [19]. In sum about external issues in assessment, many previous studies suggested that future assessment instruments that aimed to assess students' cognitive level, especially HOTS will start to involve students to apply/use knowledge that they have learned in a realistic practical context rather than on the remembering stage.

Comparing the previous studies above, the implementation of HOTS in the senior high school area is still lacking. By looking through on the needs, it is seen that written assessment is hardly considered to be able to measure HOTS properly but still being the common instrument 
type in measuring students' cognitive. As the previous studies struggles with the occurring problems, this research intended to analyze the need of assessment instruments infused with cognitive competences which aimed for the 11th grade English classes in senior high school level via online classes during Covid-19 pandemic in Bekasi.

The focus of this study is to study the need of existing assessment instruments and find out the weaknesses that require to be improved. Different with previous study which only investigated the problems, this study mainly focused on the need to improve the coherence between existing assessment instruments in 11th grade senior high school and cognitive competences indicators. By that, the research question proposed to raise the need for analysis will be based on to what extent do the existing assessment instruments for 11th grade English classes of senior high school employ the cognitive competences?

The result of the present research expectedly can provide beneficial information for the institutional, future researchers, and especially English teachers to have guidance in applying the cognitive competence assessment instruments to assess students' cognitive competences. Furthermore, this study is also expected to be useful references for another future researcher to further investigate or develop into the advanced prototype of cognitive competences assessment instruments.

\section{Literature Review}

\subsection{Cognitive Competence}

Cognitive competence is a fundamental survival skill which is characterized by rapid change and knowledge explosion in different fields to acquire and apply knowledge and skills; the ability to deal with new situations; the ability to apply knowledge; and to manipulate one's environment. Following the definition given by other researchers, cognitive competencies are not only limited to critical thinking and creative thinking as the core of cognitive competencies, but also problem solving. Critical thinking refers to reasoning and making inferences and creative thinking means stretching one's spectacles; evaluating multiple ideas and alternatives; and generating novel and practical ideas [20], [21].

The famous researchers in assessment have opened the way to measure critical thinking and problem solving that the students should be able to reason effectively through the use of various types of reasoning (inductive, deductive, etc.); make judgments and decisions through effectively analyze and evaluate evidence and beliefs; evaluate major alternative points of view; synthesize and make connections between information and arguments, interpret information and draw conclusions based on the best analysis; and reflect critically on learning experiences and processes. In addition, they also gave principles of problem-solving skills where the students should be able to solve different kinds of non-familiar problems in both conventional and innovative ways and identify and ask significant questions that clarify various points of view and lead to better solutions [22].

However, the other part of cognitive competencies which was called creative thinking and innovation also included in cognitive competencies assessment. In the 21 st century era, people are forced to be able to innovate new series, better processes, and improved products. Then, creative knowledge is required in better-paying jobs. It can be concluded that creativity and innovation are very important as a part of 21 st century skills. Creativity is a skill that everyone is born with, thus people call it imagination. People from various backgrounds and educational 
specialists have made creative and innovative contributions to all aspects of art, culture, science, and knowledge from time to time. Although youth can take few professions such as theoretical mathematics and sports, there is no age limit to creative work. Creativity and innovation can be developed by learning environments that adopt questioning, patience, openness to fresh ideas, high levels of trust, and learning from mistakes. Creativity can be developed through practice over time.

Therefore, the most effective ways to develop creative skills is through design challenge projects in which students must invent solutions to real-world problems where the students should be able to think creatively through the use of a wide range of idea creation techniques (such as brainstorming), create novel, new and worthwhile ideas (both incremental and radical concepts), Elaborate, refine, analyze and evaluate their own ideas in order to improve and maximize creative efforts [22].

Moreover, the sub domain where students have to work creatively with others by develop, implement and communicate new ideas to others effectively; be open and responsive to new and diverse perspectives; incorporate group input and feedback into the work; demonstrate originality and inventiveness in work and understand the real-world limits to adopting new ideas. They should be able to view their failure as an opportunity to learn; and understand that creativity and innovation is a long-term process of small successes and frequent mistakes. Then, they mentioned another sub domain called implement the innovations by taking an action on creative ideas to make a tangible and useful contribution to the field in which the innovation will occur [22].

\subsection{Assessment}

Assessment refers to the systematic process of evaluating and measuring collected data and information on students' language knowledge, understanding and ability in order to improve their language learning and development [23]. In addition, assessment is an activity of implementing methods and instruments to collect the information regarding the students' learning progress which can be done through a lot of ways other than testing [24]. Meanwhile, test purposes are to render information to aid in making intelligent decisions about possible course of actions, place learners into classes, discover how much they achieved, diagnose difficulties, through tests, increase in motivation, and a test is selected for particular situations [25].

To contrast the types of instruments that planned to be designed and aimed for assessing the cognitive competences, especially HOT, information regarding what else are the assessment instruments that are available, and which instruments that are suitable for assessing HOT is required. There are two kinds of assessments called Formative and Summative assessment [26]. In Formative assessment, it is aimed to diagnose students' ability. The best instruments that should be used to do Formative assessment are pre-tests that focused on content and ability, self-assessments that aimed to identify skills and competencies, discussion board responses that focused on the specified content, and assessing through Interview which must be done briefly, privately, and at least done in 10 minutes.

Therefore, formative assessment includes observations in the classroom activities, homework exercises to review and prepare for the exams and class discussions, reflections journal that reviewed periodically in the semester, question and answer sessions which can be formal, planned and informal, or even spontaneous, applying conferences between the instructor and student, performing in-class activities where students informally present their results, or even Students' feedback that collected periodically. Meanwhile for the summative assessment, the instruments are covered on major examinations, final exam, term papers, projects, portfolios, 
performance assessment, students' evaluation to track teaching effectiveness, and lastly instructor self-evaluation [23]-[25].

\section{Methodology}

This study applied content analysis using a qualitative method related to the aim is to reveal whether the instruments assessment in 11th Grade English Classes of Senior High School consist of cognitive competences. Meanwhile, the setting of this research was in two senior high schools in Bekasi which focused on the 11th grade English classes. This area was selected in order to investigate the employment of cognitive competences in the existing assessment instruments. Using purposeful sampling, the participants of this research consisted of the whole 11th grade English teachers as purposive sampling aimed to gain the complete data that was able to develop the current issues that took place with the investigated situation [27].

Thus, the information about the existing assessment instruments is required to be analyzed to track whether the assessment instruments for 11th grade senior high schools have already employed the cognitive competences specifically HOTS (> C4 - C6) or not, so that it will be in line with the needed analysis and HOTS measurement. Further, at the beginning, this study would like to implement the need analysis in order to know what cognitive competences assessment instruments that currently needed to be matched the requirements that are beneficial for school.

The data were in the form of words, sentences, or phrases which can be found in the existing assessment instruments commonly used to test the students. Therefore, the instruments that researchers used to formulate the findings are Assessments Instruments Types, HOTS indicators, Revised Bloom's Taxonomies Domain, and the Cognitive Competencies indicators [4], [22], [26].

In analyzing data, the researchers followed content analysis steps suggested as in [28]. These steps mentioned six steps in data making analysis that help researchers to answer research questions which includes Unitizing, Sampling, Recording/coding, reducing data to manageable representations, Abductively inferring contextual phenomena, and lastly Narrating the answer to the research question [28].

\section{Findings and Discussions}

After the data were processed, this research would like to serve the processed data in the form of tables to highlight the findings of this research clearly. In that case, the following tables delineates the data obtained from the teachers regarding the assessment instruments used. The type of the assessment instruments were summative assessments in the form of Final Exam and Students' Evaluation for Mid-Term Test which is based on the assessment instrument types classified by [23]. The data were collected from 2 different senior high schools in Bekasi City. To measure the cognitive domain level of each assessment instrument, this research took a deeper analysis with a complete indicator in (see Table 4.2) where each assessment item in the assessment instruments were analyzed and classified to find out the cognitive domain level [4].

From cognitive domain level analysis, it can be explained that Data 1 which is a Mid-Term Test in the form of Essay has 16 assessment items. From the table it can be seen that this type of assessment (essay) has a low count of LOTS (C1-C3). There were 3 assessment items for C1 
(Remember) as this type of assessment items commands students to reread the given text to find the answer which is closely related with keywords "state", "identify", and "outline". Further, there was 1 assessment item for $\mathrm{C} 2$ (Understand) where the question raised in number 3 of the assessment item stated "What lesson was never forgotten by the writer?" means that the students have to reread the text but "interpret", "review", "summarize", and "relate" the text logically to answer the question correctly.

The table also shows that only 4 assessment items listed in the LOTS out of 16 . While the rest 12 items were classified as C4 (Analyze) level where the Essay instruct students to analyze and categorize the given items to answer the questions properly, and C5 (Evaluate) where the question instruct students to evaluate, justify, and judge the impact of the given text by their own words. At this rate, this Essay assessment model has a HOTS cognitive domain which dominates more than the LOTS cognitive domain. (See Table 4.2)

Contrasting with other assessment instruments formed in the Multiple-Choice type in Data 2, 3 and 4, the essay type has a better cognitive level. The details of cognitive domain level that dominated in the three multiple choices were LOTS ranging from $\mathrm{C} 1$ (Remember) where most of the assessment items instructed students to "retell / state", "define", "complete" and "describe". Then in C2 (Understand) where the assessment items instructed students to "review", "interpret", "translate", "arrange", "conclude", and "summarize" in order to answer the questions.

Furthermore, in C3 (Apply) the students were asked to apply, or use the knowledge that they have learned by filling in the blank of the assessment items (See Table 4.2). But, different with Data 4, even though it is in a multiple-choice form, it has already applied the HOT ranging from C4 - C6 even if the amount of LOT is still dominating over the HOT. (See Table 4.2)

By the explanation above, it can be seen that the multiple-choice assessment instruments cannot completely promote the Higher Order Thinking (HOT) as the Lower Order Thinking (LOT) cognitive domain dominates more. Meanwhile Data 1 in the Essay form which consists of 16 assessment items for mid-term tests showed that HOT ranged on C4 / analysis type dominates more than LOT category. By that, there is a need to improve the existing assessment instruments that employ the higher cognitive domain which is away from the traditional assessment.

While the data in this research did not fully employ the cognitive domain taxonomy, further specification is required to fully explore the cognitive competences of the 21 st century. The following table below is based on the Cognitive Competences designed by Trilling and Fadel which is being used to track the cognitive competences in the assessment instruments.

The implementation of cognitive competences in assessment instruments not fully applied in both schools. Even though most assessment instruments almost employed the Critical Thinking Indicator, only 2 assessment instruments reached one of the Sub Indicators of Creative Thinking Indicator. In that case, to highlight the need of this study, it is required for the assessor to develop the assessment instrument which has the HOT level as the basis to infuse the Cognitive Competences. (See Table 4.3)

Based on the explanation from the data reducing and inferring stages of the tables above, there are some findings that can be used to answer the research question of this study and discuss each finding with the theories by experts and other previous studies that cited in this study as follows:

4.1 The need of HOT cognitive domain (C4-C6) infusion in the assessment instruments.

After analyzing the data, it is found that the cognitive domain applied in the assessment instruments are majoring in the Lower Order Thinking (LOTS) cognitive domain. In that case 
the HOTS (C4-C6) must be applied more in the 11th grade senior high schools' students' assessment instruments in order to provide the appropriate cognitive competences and the $21 \mathrm{st}$ Century Skills which include critical thinking and creative thinking. This finding is in line with the findings from [6], [8], [11], [12] where the need analysis result claimed that multiple choice assessment is not suitable to be infused with HOT as studies above conclude that most cognitive level of assessment instruments, especially multiple-choice items ranging from junior high school to college (bachelor) level including the senior high school level that currently being studied were relatively low.

In that case, it is required for the assessment designer to input the higher cognitive domain in the assessment to be closer with the 21 st century cognitive competences. Contrasting with the previous studies above, it can be concluded that assessment instruments infused with HOT cognitive domain in senior high school level are needed as the indicators in C4 / Analyzing, C5 / Evaluating, and C6 / Creating have similarities with Cognitive Competences Indicators of Critical Thinking and Creative Thinking. By that, if the cognitive domain does not apply the HOT, it will be impossible also for the assessment instruments to employ the Cognitive Competences as one of the 21st Century Skills.

\subsection{The need of implementing practical-based assessment instruments infused with HOT cognitive domain level.}

The second findings of this study indicates that Multiple Choice assessment items did not fully provide the HOT and quite far from Cognitive Competences perfection criteria, in that case, a need to develop a new kind of assessment instruments away from Multiple Choice is required. Even though developing the Multiple-Choice instruments with harder distractors to promote cognitive domain, multiple choice assessment still claimed employ the lower order thinking domain [8], [9].

Further, Multiple Choice is not recommended to be used for promoting HOTS cognitive domain where practical-based assessment instruments infused with cognitive competences is crucial instead of only depending on traditional assessment [6], [8], [9]. Furthermore, supported by other previous studies the need of Alternative Assessment Instruments form which promotes HOTS cognitive domain is exceedingly compulsory [13]-[19].

In sum, the need to include the practical-based assessment to promote the cognitive competences indicators is crucial. It can be done through remodifying the existing cognitive competences assessment instruments which still applies the traditional assessment into a practical-based, and develop the assessment by infusing the HOT cognitive domain and indicators of cognitive competences.

\section{Conclusion and Recommendation}

The assessment instruments are essential aspects in the teaching and learning process not only for students, but also for the teachers or educators to inspect how further the students can acquire the knowledge, skills, or competences in classrooms. In the Indonesia context, the assessment instruments that applied for mid-test and final tests were still under the lower order cognitive domain, as most of the instrument assessment existed used multiple choice.

This study only covered a small area of research which means that the result of this study cannot be generalized as further studies which covered a larger area and more data are required 
in order to reflect with the findings of this study. In that case it is important for future researchers to focus on developing a new model of cognitive competences assessment instruments.

Some limitations in conducting this study are included. The first limitation is the settings of this study where this study will only focus on two senior high schools in East Jakarta. The second limitation is the participants where this study only aimed to take any available 11th grade English teachers from the selected two senior high schools in Bekasi that willingly participated as the participants of this study. These limitations are wrapped up upon the researcher's inability in time and budget during the conduction.

\section{Acknowledgments}

The researchers would like to thank the teachers who willingly participated in this research by providing the required data. Their valuable contributions are very well appreciated to support this research.

\section{References}

[1] I. Tosuncuoglu, "Importance of Assessment in ELT," J. Educ. Train. Stud., vol. 6, no. 9, p. 163, 2018.

[2] J. M. Royer, C. A. Cisero, and M. S. Carlo, Techniques and Procedures for Assessing Cognitive Skills, vol. 63, no. 2. 1993.

[3] P. Griffin, B. McGaw, and E. Care, Assessment and teaching of 21st century skills, vol. 9789400723245. 2012.

[4] S. M. Brookhart, How to Assess High-order Thinking Skills in Your Classroom. California: ASCD Publication, 2010.

[5] C. Covacevich, "How to select an instrument for assessing student learnin," Inter-American Dev. Bank, vol. No. IDB-TN, no. December, 2014.

[6] K. T. Dewi, "Developing assessment instrument-based curriculum 2013 for teaching micro teaching in English education department of Undiksha,” Int. J. Soc. Sci. Humanit., vol. 2, no. 3, pp. 95-106, 2018.

[7] N. Erna, "Developing Cognitive English Test on Recount Text Material," Seltics, vol. 3, no. 2, pp. 55-64, 2020.

[8] E. Akib and M. A. Muhsin, "Critical thinking in cognitive domain: Exploring assessment of English teaching at pandemic period of covid-19," JEES (Journal English Educ. Soc., vol. 5, no. 2, pp. 178-184, 2020.

[9] W. Sumarni, K. I. Supardi, and N. Widiarti, "Development of assessment instruments to measure critical thinking skills," IOP Conf. Ser. Mater. Sci. Eng., vol. 349, no. 1, 2018.

[10] N. Agustina, Y. Efisa, and H. Oktawati, "AN ANALYSIS OF STUDENTS' COGNITIVE ASSESSMENT BASED ON BLOOM TAXONOMY AT EIGHTH GRADES OF SMPN 33 SAROLANGUN ANDSMPN 35 SAROLANGUN ACADEMIC YEARS 2018 - 2019,” English Educ. Progr. J., vol. 2, no. 2, pp. 11-15, 2019.

[11] Y. Abosalem, "Assessment techniques and students' higher-order thinking skills," ICSIT 2018 9th Int. Conf. Soc. Inf. Technol. Proc., no. March, pp. 61-66, 2015.

[12] Y. M. Heong, W. B. Othman, J. B. M. Yunos, T. T. Kiong, R. Bin Hassan, and M. M. B. Mohamad, "The Level of Marzano Higher Order Thinking Skillsamong Technical Education Students," Int. J. Soc. Sci. Humanit., vol. 1, no. 2, pp. 121-125, 2011.

[13] E. Bell, R. Allen, and P. Brennan, "Assessment of higher order thinking skills: A discussion of the data from the 2001 random sampling exercise and a workshop for teachers," pp. 1-41, 2001.

[14] S. Shenoy, "Assessment tools to differentiate between language differences and disorders in English language learners," Berkeley Rev. Educ., vol. 5, 2014.

[15] M. Razmawaty and O. Lebar, "Freedom of Speech: A Comparative Study between Islam and Malaysian Laws,” Int. J. Acad. Res. Bus. Soc. Sci., vol. 7, no. 2, pp. 466-476, 2017. 
[16] K. P. Ng, H. J. Chiew, L. Lim, P. Rosa-Neto, N. Kandiah, and S. Gauthier, "The influence of language and culture on cognitive assessment tools in the diagnosis of early cognitive impairment and dementia," Expert Rev. Neurother., vol. 18, no. 11, pp. 859-869, 2018.

[17] E. Toyoda, "Assessment of Higher-Order Thinking Skills Required for Intercultural Learning," vol. 1, pp. 1-20, 2018.

[18] T. Sulaiman, S. S. A. Rahim, M. N. Hakim, and R. Omar, "Teachers' perspectives of assessment and alternative assessment in the classroom," Int. J. Innov. Technol. Explor. Eng., vol. 8, no. 7, pp. 426-431, 2019.

[19] S. Sheehan and S. Munro, "Classroom Assessment: The Development of Teachers' Cognitions," Br. Counc., pp. 1-16, 2019.

[20] R. C. F. Sun and E. K. P. Hui, "Cognitive competence as a positive youth development construct: A conceptual review," Sci. World J., vol. 2012, pp. 21-23, 2012.

[21] D. T. L. Shek et al., "Development and evaluation of a positive youth development course for university students in Hong Kong," Sci. World J., vol. 2012, no. April, 2012.

[22] B. Trilling and C. Fadel, "Bernie Trilling, Charles Fadel-21st Century Skills_ Learning for Life in Our Times -Jossey-Bass (2009),” J. Sustain. Dev. Educ. Res., vol. 2, no. 1, p. 243, 2009.

[23] C. Coombe, How Language Assessment Works. London: UK: British Council, 2018

[24] J. Myles, "Second Language Writing and Research: The Writing Process and Error Analysis in Student Texts.," Tesl-Ej, vol. 6, no. 2, 2002.

[25] G. Fulcher and F. Davidson, Language Testing and Assessment. USA: Routledge, 2007.

[26] K. M. Scott, O. A. Barbarin, and J. M. Brown, "From Higher Order Thinking to Higher Order Behavior: Exploring the Relationship Between Early Cognitive Skills and Social Competence in Black Boys," vol. 83, no. 2, pp. 185-193, 2013.

[27] R. C. Richey and J. D. Klein, Desing and Development Research: Methods, Strategies, and Issues. New York: Routledge, 2010.

[28] K. Krippendorff, Content Analysis: An Introduction to Its Methodology (2nd ed.)., vol. 13, no. 2. 2010. 